\title{
Peer Review of "Utility of the ROX Index in Predicting Intubation for Patients With COVID-19-Related Hypoxemic Respiratory Failure Receiving High-Flow Nasal Therapy: Retrospective Cohort Study"
}

Mukul Sehgal, MD, FAAP

\section{Related Articles:}

Preprint (medRxiv): https://www.medrxiv.org/content/10.1101/2020.06.30.20143867v2

Preprint: https://preprints.jmir.org/preprint/29062

Authors' Response to Peer-Review Reports: https://med.jmirx.org/2021/3/e31892/

Published Article: https://med.jmirx.org/2021/3/e29062/

(JMIRx Med 2021;2(3):e31896) doi: 10.2196/31896

This is a peer-review report submitted for the paper "Utility of the ROX Index in Predicting Intubation for Patients With COVID-19-Related Hypoxemic Respiratory Failure Receiving High-Flow Nasal Therapy: Retrospective Cohort Study”.

\section{Round 1 Review}

\section{General Comments}

This paper [1] is an important resource for the use of high-flow nasal cannula in patients with COVID-19 and provides important insights on the current COVID-19 pandemic. Respiratory support for patients with COVID-19 is an important topic for critical patients.

\section{Specific Comments}

The paper can be improved in certain areas like methods and design. Also, there is some duplication of the results in the discussion.

\section{Major Comments}

1. Inclusion criteria need to be well defined.

2. Initial HFNT (high-flow nasal therapy) settings: there is a discrepancy between the flow mentioned in the Method and Design section (35 L/min) and that mentioned in the Results section (33.5, SD $11.7 \mathrm{~L} / \mathrm{min}$ of flow). Can you please clarify?

3. The discussion needs to be rewritten. It seems like a duplication of the results, especially the first paragraph.

\section{Minor Comments}

1. The dose of methylprednisolone should read "mg/kg."

2. Screening criteria: were the patients identified with high clinical suspicion based on computed tomography COVID-19 negative? If yes, please mention that in the paper.

3. In the sentence, "At initiation of HFNC, a ROX of $<5$ was predictive of intubation (OR 2.137, $P=.051$ )," what was the confidence interval? The $P$ value is greater than .05 .

4. In the sentence, "Any change in ROX of less than or equal to zero after HFNT initiation over 24 hours was also predictive of intubation," what do you mean by change less than or equal to zero? This sentence is a little confusing.

5. There are multiple references of $\mathrm{ROC}=0.77$ and $\mathrm{ROC}=0.86$; did you mean AUC (area under the ROC curve) or C-statistic?

\section{Conflicts of Interest}

None declared.

\section{Reference}

1. Patel M, Chowdhury J, Mills N, Marron R, Gangemi A, Dorey-Stein Z, et al. Utility of the ROX Index in Predicting Intubation for Patients With COVID-19-Related Hypoxemic Respiratory Failure Receiving High-Flow Nasal Therapy: Retrospective Cohort Study. JMIRx Med 2021 Aug 18;2(3):e29062 [FREE Full text] [doi: 10.2196/29062] [Medline: 2137297] 
Edited by E Meinert; this is a non-peer-reviewed article. Submitted 08.07.21; accepted 08.07.21; published 27.08.21.

Please cite as:

Sehgal $M$

Peer Review of "Utility of the ROX Index in Predicting Intubation for Patients With COVID-19-Related Hypoxemic Respiratory Failure Receiving High-Flow Nasal Therapy: Retrospective Cohort Study"

JMIRx Med 2021;2(3):e31896

URL: https://med.jmirx.org/2021/3/e31896

doi: $\underline{10.2196 / 31896}$

PMID:

CMukul Sehgal. Originally published in JMIRx Med (https://med.jmirx.org), 27.08.2021. This is an open-access article distributed under the terms of the Creative Commons Attribution License (https://creativecommons.org/licenses/by/4.0/), which permits unrestricted use, distribution, and reproduction in any medium, provided the original work, first published in JMIRx Med, is properly cited. The complete bibliographic information, a link to the original publication on https://med.jmirx.org/, as well as this copyright and license information must be included. 